ONLINE MUTATION REPORT

\title{
Identification of mutations in the AIPL1, CRB1, GUCY2D, RPE65, and RPGRIP1 genes in patients with juvenile retinitis pigmentosa
}

\author{
J C Booij, R J Florijn, J B ten Brink, W Loves, F Meire, M J van Schooneveld, P TVM de Jong, \\ A A B Bergen
}

Objective: To identify mutations in the AIPLI, CRB 1, GUCY2D, RPE65, and RPGRIP1 genes in patients with juvenile retinitis pigmentosa.

Methods: Mutation analysis was carried out in a group of 35 unrelated patients with juvenile autosomal recessive retinitis pigmentosa (ARRP), Leber's congenital amaurosis (LCA), or juvenile isolated retinitis pigmentosa (IRP), by denaturing high performance liquid chromatography followed by direct sequencing.

Results: All three groups of patients showed typical combinations of eye signs associated with retinitis pigmentosa: pale optic discs, narrow arterioles, pigmentary changes, and nystagmus. Mutations were found in $34 \%$ of patients: in CRB1 (11\%), GUCY2D (11\%), RPE65 (6\%), and RPGRIP1 (6\%). Nine mutations are reported, including a new combination of two mutations in CRB1, and new mutations in GUCY2D and RPGRIP1. The new GUCY2D mutation (c.3283delC, p.Pro1069ArgfsX37) is the first pathological sequence change reported in the intracellular C-terminal domain of GUCY2D, and did not lead to the commonly associated LCA, but to a juvenile retinitis pigmentosa phenotype. The polymorphic nature of three previously described (pathological) sequence changes in AIPLI, CRB 1, and RPGRIPI was established. Seven new polymorphic changes, useful for further association studies, were found. Conclusions: New and previously described sequence changes were detected in retinitis pigmentosa in CRB 1, GUCY2D, and RPGRIPI; and in LCA patients in CRB 1, GUCY2D, and RPE65. These data, combined with previous reports, suggest that LCA and juvenile ARRP are closely related and belong to a continuous spectrum of juvenile retinitis pigmentosa.

$\mathrm{R}$ etinitis pigmentosa (RP) denotes a group of hereditary retinal dystrophies with a worldwide prevalence of approximately 1 in 4000 . The disease is clinically and genetically very heterogeneous. ${ }^{1}$ The phenotype of the juvenile form of RP shows overlap with Leber's congenital amaurosis (LCA), an autosomal recessive retinal dystrophy with a worldwide prevalence of 1 in $35000 .{ }^{2}$ Patients with juvenile RP are considered to have good central vision during the first decade of life, while the age of onset of severe visual impairment in LCA ranges from birth to the first year of life. ${ }^{3}$ Retinitis pigmentosa is characterised by night blindness, progressive constriction of the visual field, pale discs, retinal vascular narrowing, pigmentary changes in the retina, and reduced electroretinogram (ERG) amplitudes. ${ }^{5}$ LCA is characterised by congenital nystagmus, a decreased pupillary response, pigmentary changes in the retina (although the fundoscopic appearance is initially normal), and reduced ERG amplitudes. ${ }^{2}{ }^{6}$ Various intermediate phenotypes between LCA and RP are known and are sometimes described as "early onset severe rod-cone dystrophy" or "early onset retinal degeneration." ${ }^{3}$ The clinical distinction between the subtypes of RP is not always clear, and the diagnostic criteria are frequently not agreed upon between ophthalmologists. ${ }^{7}$ In $29 \%$ of patients, RP is part of a syndrome, such as Usher's or Bardet-Biedl's. ${ }^{1}$ Of the non-syndromal RP cases in the Netherlands, $37 \%$ is isolated (IRP); of the remainder, the transmission mode is autosomal recessive in $30 \%$, autosomal dominant in $22 \%$, and $\mathrm{X}$ linked in $10 \% .{ }^{8}$ In addition, several unusual inheritance patterns-such as digenic inheritance ${ }^{9}$ and uniparental isodisomy, ${ }^{10}$ in which a child inherits two copies of a single parental chromosome-have been observed. LCA is most often inherited in autosomal recessive mode. ${ }^{2}$

The molecular genetic diversity within the different phenotypes of RP is also well documented. ${ }^{3411}$ At least 17 genes are currently known to be involved in autosomal recessive RP (ARRP), while five additional loci have been identified. ${ }^{12}$ So far, mutations can only be identified in approximately $50 \%$ of ARRP and LCA patients. Eight LCA genes have been cloned so far: AIPLI, ${ }^{13}$ CRBI, ${ }^{14} C R X,{ }^{15}$ GUCY2D, ${ }^{16}$ RDH12, ${ }^{17}$ RPE65, ${ }^{18}$ RPGRIP1, ${ }^{19}$ and TULP1. ${ }^{20}{ }^{21}$ The genetic overlap between ARRP and LCA is illustrated by the fact that all but three of these genes (AIPLl, CRX, and RPGRIP1) were previously implicated in ARRP $\left(C R B 1,{ }^{14} 22\right.$ GUCY2D, ${ }^{16}{ }^{23}$ RDH12, ${ }^{24}{ }^{25}$ RPE65, ${ }^{48}$ and TULPI ${ }^{26-28}$ ).

To illustrate the diversity and complexity of genotypephenotype correlations in RP and LCA, two examples are mentioned here. Previously, a correlation was suggested between mutations in the RPE65 gene and a phenotype consisting of severe visual impairment within the first year of life, with a measurable visual acuity at the age of six to 10 years, and congenital nystagmus in three of four patients. However, no such correlation was observed in another study. ${ }^{3}$ Similarly, two parents diagnosed with RP had a daughter who carried a homozygous RPE65 mutation and who was reported to have LCA (absent or severely diminished vision within the first year of life) ${ }^{4}$

In summary, there appears to be significant overlap between juvenile ARRP and LCA in both a clinical and a genetic sense. This makes the clinical distinction between juvenile ARRP and LCA difficult if not impossible. ${ }^{72}$ We hypothesised that mutations in the five most common LCA genes could also be responsible for juvenile ARRP. ${ }^{72}{ }^{28}{ }^{29} \mathrm{We}$

Abbreviations: ARRP, autosomal recessive retinitis pigmentosa; DHPLC, denaturing high performance liquid chromatography; IRP, juvenile isolated retinitis pigmentosa; LCA, Leber's congenital amaurosis; RP, retinitis pigmentosa 
Table 1 Characteristics of cloned genes implicated in recessive Leber's congenital amaurosis according to published reports

\begin{tabular}{llllll}
\hline Gene & $\begin{array}{l}\text { Chromosome } \\
\text { location }\end{array}$ & Described in & $\begin{array}{l}\text { Found in } \\
\text { (\%) of patients }\end{array}$ & $\begin{array}{l}\text { Reference* } \\
\text { Primer } \\
\text { referencet }\end{array}$ \\
\hline AIPL1 & $17 \mathrm{p} 13.2$ & LCA & $5-10$ & 13 & This study \\
CRB1 & $1 \mathrm{q} 31.3$ & LCA, ARRP & $9-13$ & 14 & 14 \\
CRX & $19 \mathrm{q} 13.32$ & LCA & $1-3$ & 15 & 16 \\
GUCY2D & $17 \mathrm{p} 13.1$ & LCA, ARRP & $10-20$ & 16 & 17 \\
RDH12 & $14 \mathrm{q} 24.1$ & LCA, ARRP & 4 & 18 & 4 \\
RPE65 & $1 \mathrm{q} 31.2$ & LCA, ARRP & $6-16$ & 19 & 31 \\
RPGRIP1 & $14 \mathrm{q} 11.2$ & LCA & $4-6$ & 20,21 & \\
TULP1 & $6 \mathrm{p} 21.31$ & LCA,ARRP & Several families & \\
\hline
\end{tabular}

*References first describing the cloning of the respective genes.

tReferences describing the primers we used.

ARRP, autosomal recessive RP, IRP, isolated RP, LCA, Leber's congenital amaurosis.

therefore tested our ARRP, IRP, and LCA patients for mutations in the following "LCA" disease genes: AIPL1, CRB1, GUCY2D, RPE65, and RPGRIP1.

\section{METHODS \\ Patients}

This study was performed in agreement with the declaration of Helsinki. Patients included in the study or their legal representatives gave permission for blood to be drawn for mutation detection. All patients diagnosed with ARRP and IRP with a disease onset before age 20 years, as well as all patients with an LCA diagnosis, and presenting to the Netherlands Ophthalmic Research Institute (NORI) were included in the study. Most patients were Dutch, four were Belgian, one originated from Turkey, one had a Mexican and a Dutch parent, and one had an Indonesian and a Dutch parent.

The diagnoses of RP and LCA were based on a combination of the following criteria.

For RP, the criteria were: (subjective) night blindness, a pale optic disc, narrow arterioles, pigmentary changes, ERG amplitude reduction $(>50 \%)$, and visual field abnormalities, compatible with RP. ${ }^{1}$ Patients were considered to have juvenile RP when their first reported symptoms occurred before the age of 20 .

For LCA, the criteria were: signs of blindness or severe visual impairment from birth or within the first year of life, an ERG reduction of more than 50\%, and congenital nystagmus. ${ }^{1}$

Patients were diagnosed with autosomal recessive inheritance when they had two unaffected parents and one or more affected siblings or consanguineous parents. Patients were diagnosed with IRP when no affected relatives were known, and there was no parental consanguinity, or no inheritance pattern could be established. Patients were excluded when their family tree showed evidence of autosomal dominant or $X$ linked inheritance, ${ }^{1}$ or when their RP or LCA was part of a syndrome.

\section{Mutation detection}

The DNA isolated from peripheral blood was stored at $4{ }^{\circ} \mathrm{C}$ until use. ${ }^{30}$ The following primers were used for the amplification of AIPL1: exon 1 forward (IF) cctggtccctgtcttc $\mathrm{ttt}$, exon 1 reverse (IR) tgttgaaagctgctgtgggg, $2 \mathrm{~F}$ ggcettgaaca gtgtgtcta, 2R gagcccagaaaagactagtc, $3 \mathrm{~F}$ ggccttttatggcccaccta, 3R ctgtccctctccagtgctgg, 4F tggggtccetgcctcactga, 4R ccccaga gtcagcgccactt, 5F aagtggcgctgactctgggg, 5R tgtctccgtggccet gggct, 6F cctctgaggctgggaaggga, 6R gaccaggccacttgctccct. Primers used for CRB1, GUCY2D, RPE65, and RPGRIPI along with their characteristics are referred to in table 1.

The length of the polymerase chain reaction (PCR) product was checked on a $2 \%$ agarose gel, after which it was mixed with an equal volume of PCR product from a healthy control person in order to detect homozygous sequence changes. This was followed by a heteroduplex formation step before samples were analysed for mutations using denaturing high performance liquid chromatography analysis (DHPLC) (Transgenomic, Santa Clara, California, USA) at two or three different temperatures.

Exons showing a DHPLC pattern that differed from a healthy control, and the healthy control itself, were reamplified and purified using a QIA-quick PCR purification kit (Qiagen, Valencia, California, USA) for direct sequencing. A sequence reaction $\left(25\right.$ cycles consisting of 10 seconds at $96^{\circ} \mathrm{C}$, five seconds at $50^{\circ} \mathrm{C}$, and four minutes at $60^{\circ} \mathrm{C}$ ) was carried out using forward and reverse primers separately (table 1). Sequence products were precipitated with $75 \%$ isopropanol and dissolved in template suppression reagent, after which the products were denatured at $94^{\circ} \mathrm{C}$ for two minutes. Samples were subsequently analysed using the ABI-310 (Applied Biosystems, Foster City, California, USA). We described mutations using the following Genbank reference cDNA sequences ${ }^{32}$ : AIPL1, gi6716706; CRB1, NM_012076.2; GUCY2D, NM_000180.1; RPGRIP1, NM_020366. 2 ; RPE65, gi3077820; the first A of the ATG was chosen as nucleotide +1 , and the ATG as codon $+1 . .^{33}$

\section{Definition of pathogenicity}

We considered a sequence variation to be pathogenic when we found it exclusively in patients and not in at least 120 chromosomes from 60 control persons. In addition, we made a literature based prediction of the effect of a new mutation, using the description of mutations in or the function of similar domains. We considered sequence variations polymorphic when their allele frequency was not significantly higher in patients than in control persons, or when they did not co-segregate with the disease phenotype in a family. Our patient group consisted of 35 patients and our control group of at least 60 healthy persons ( 120 chromosomes).

\section{RESULTS}

\section{Patients}

Our mutation screening panel consisted of 17 ARRP, nine LCA, and nine IRP patients. Table 2 shows the clinical characteristics of the 12 patients in whom we found mutations.

Visual field changes corresponding to RP were seen in ARRP, IRP, and LCA patients. As expected, an ERG reduction of at least $50 \%$ was reported in nearly all RP and LCA patients (data were missing for two patients). Nystagmus, corresponding to an LCA phenotype, was seen in all LCA patients and in one IRP patient. The RP and LCA patients, in whom no mutations were found, showed similar overlapping clinical features (data not shown). 

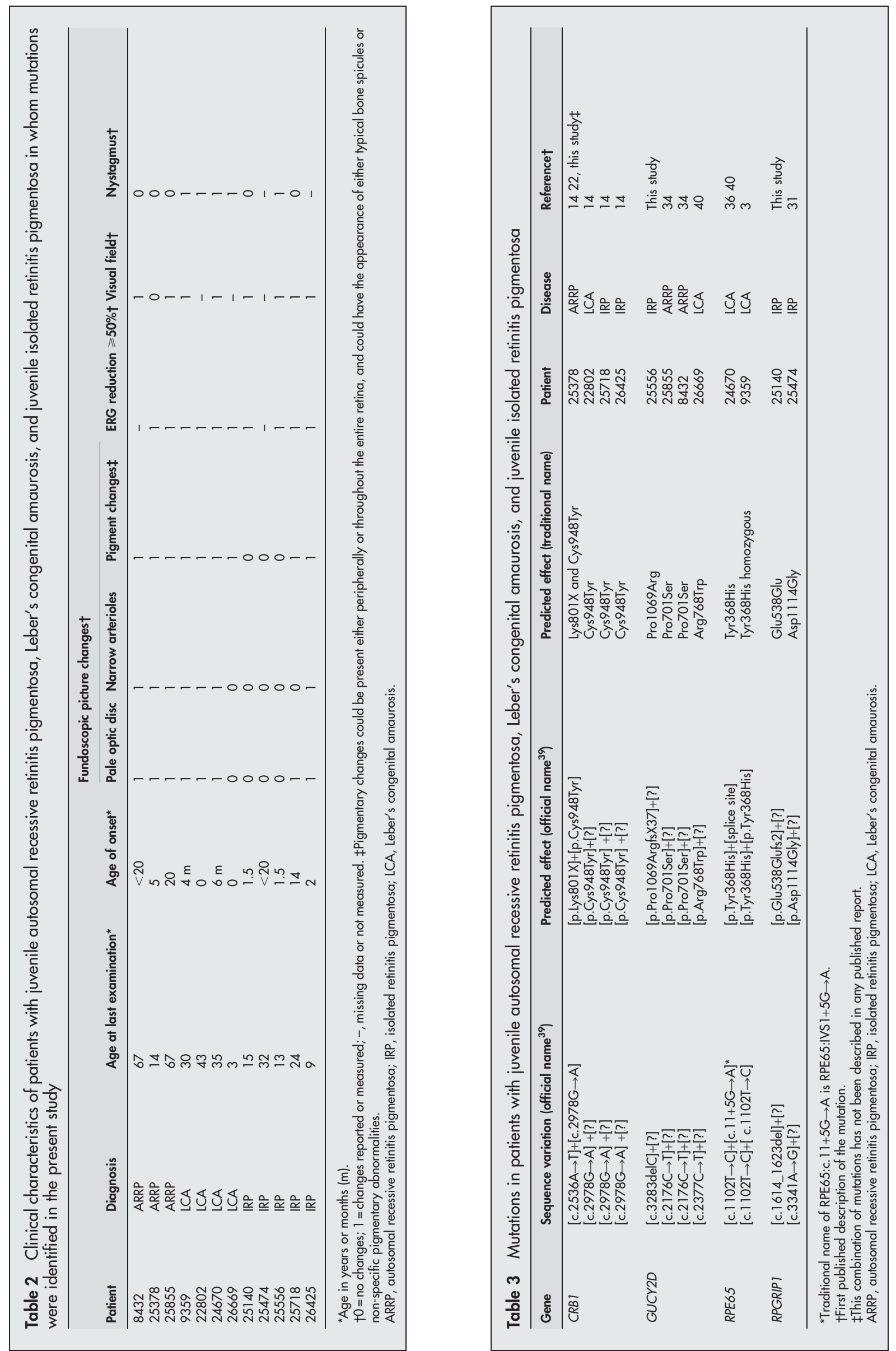

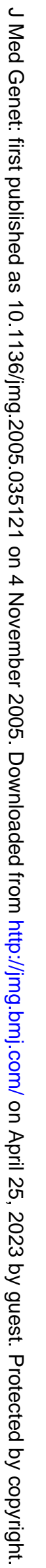




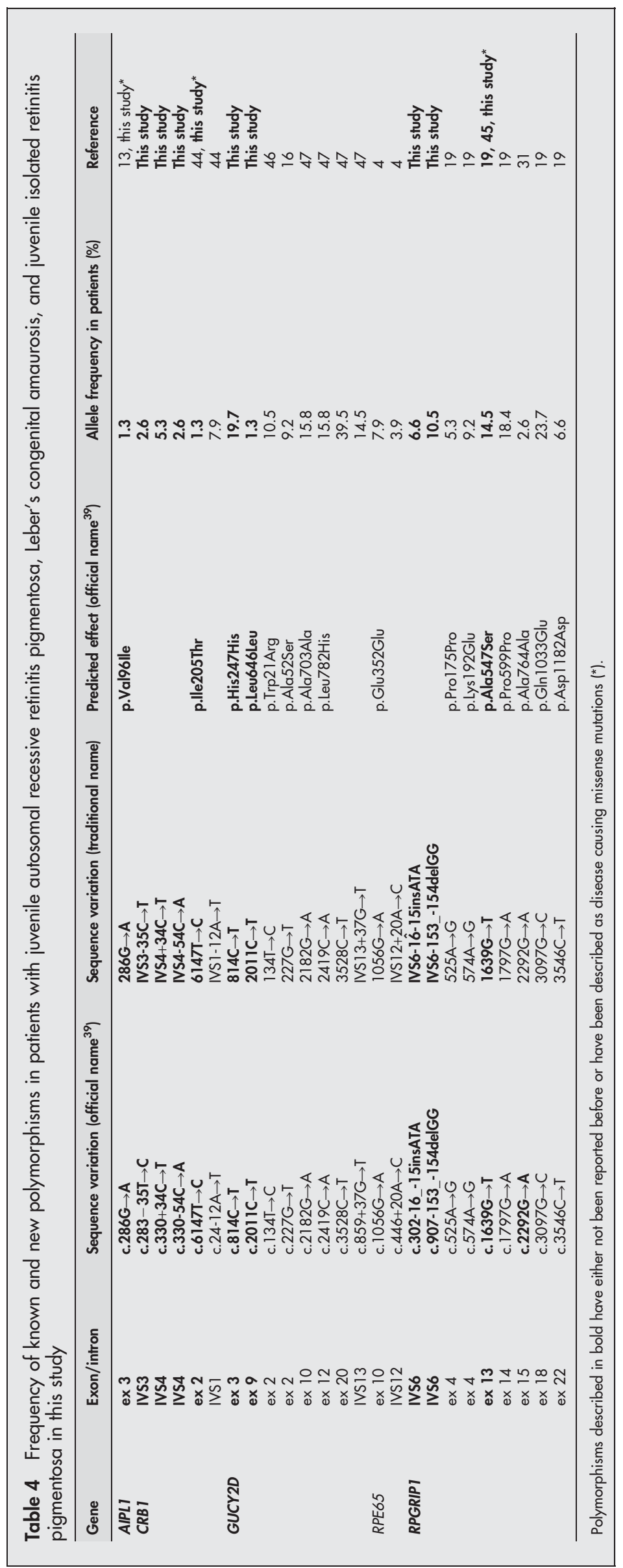




\section{Mutations}

We identified nine different mutations in 12 patients $(34 \%)$, in the CRBI (11\%), GUCY2D (11\%), RPE65 (6\%), and RPGRIPI $(6 \%)$ genes. In three of these patients two mutations were found (9\%)—one patient had a homozygous mutation and two had a compound heterozygous mutation. In nine patients we detected a mutation in a single allele only. We found a mutation in three ARRP patients (17\%), in four LCA patients $(44 \%)$, and in five IRP patients $(56 \%)$. Two of the mutations identified in this study are new, and we describe a new combination of two mutations. All mutations are presented in table 3.

The first new mutation identified in this study was a heterozygous deletion resulting in a frameshift in GUCY2D:c.3283delC, p.Prol069ArgfsX37 in IRP patient 25556. This male patient had a disease onset at age 1.5 years. At age 13 he had a visual acuity of 0.1 , a severely reduced ERG, a limited visual field, and nystagmus. Cosegregation of the deletion in the family could not be determined owing to the unavailability of parental DNA. However, the deletion was not found in our control population. We also identified GUCY2D mutations in ARRP patients 25855 and 8432 (p.Pro701Ser) ${ }^{34}$ and in LCA patient 26669 (p.Arg768Trp). ${ }^{35}$

The second new mutation was a deletion causing a frameshift in RPGRIPI:cl614_1623del, p.Glu538Glufs2 in IRP patient 25140. Visual problems in this patient were noted in the second year of life; she had a visual acuity of 0.1 at the age of 15, and experienced night blindness and colour vision impairment. Fundoscopy revealed an atrophic macular area, and the ERG was severely reduced. We did not detect this deletion in our control population. In addition, we found one known RPGRIPl mutation in IRP patient 25474 (p.Aspl114Gly). ${ }^{31}$

We found a new combination of two mutations in CRBI in ARRP patient $25378 \quad\left([\mathrm{c} .2536 \mathrm{~A} \rightarrow \mathrm{T}, \text { p.Cys948Tyr }]^{14}+\right.$ [c.2978G $\rightarrow$ A, p.Lys801X] $]^{22}$ ). The age of onset was five years; at age 14, the visual acuity was finger counting, and subjective night blindness was reported. Earlier data on visual acuity and night blindness were missing. The ERG was severely reduced and the fundoscopic picture showed narrow arterioles, a pale optic disc, and pigmentary changes in the periphery. CRBI mutations were also found in LCA patient 22802 and in IRP patients 25718 and 26425 (p.Cys948Tyr). ${ }^{14}$

In the RPE65 gene we found mutations in LCA patient 9359 $([\text { p.Tyr368His }]+[\text { c. } 11+5 \mathrm{G} \rightarrow \mathrm{A}])^{35}{ }^{36}$ and in LCA patient 24670 (p.Tyr368His homozygously). We confirm the pathogenic nature of the $\mathrm{RPE} 65$ c. $11+5 \mathrm{G} \rightarrow \mathrm{A}$ sequence change. It is located in a donor splice site where the $G$ nucleotide is predicted to be conserved in $84 \%$ of primate splice sites..$^{35-37}$. In addition, we do not find it in our controls. ${ }^{38}$

\section{Polymorphic sequence changes}

We observed seven new and 15 known polymorphisms in all five genes. In addition, we established or confirmed the polymorphic nature of three sequence changes previously described as pathogenic mutations. Table 4 summarises the polymorphisms along with their allele frequency in our patient population.

We identified seven new polymorphic sequence changes which are described below. Three new intronic polymorphisms were located in the CRBI gene (c.283-35T $\rightarrow \mathrm{C}$, c.330+34C $\rightarrow \mathrm{T}$, and c.330-54C $\rightarrow \mathrm{A}$ ), and two new silent polymorphisms were found in GUCY2D (c.814C $\rightarrow \mathrm{T}$, p.His247His and c.2011C $\rightarrow \mathrm{T}$, p.Leu646Leu). In RPGRIPI a new insertion (c.302-16_-15insATA), and a new deletion (c.907-153_-154delGG) was found. Bioinformatic analysis of all intronic sequence changes did not lead to changes in the splice sites. Analysis of the silent polymorphisms did not reveal predicted changes in exonic splicing enhancers. ${ }^{41}{ }^{42}$

We identified three sequence changes of uncertain pathogenic nature. In published reports, these are tentatively described as polymorphisms. The first sequence change was AIPL1:c.286G $\rightarrow$ A, p.Val96Ile, ${ }^{13}$ with an allele frequency in patients of $1 \%$, and in matched control persons of $7 \%$ $(\mathrm{n}=122$ chromosomes). The second sequence change, CRB1:c.6147T $\rightarrow$ C, p.Ile205Thr, ${ }^{43}$ was found only once in our patient population (allele frequency $1 \%$ ). We did not find it in our controls. However, we found no co-segregation with the disease phenotype in ARRP family 21724 (fig 1). The third sequence change we identified was RPGRIPI:C.1639G $\rightarrow \mathrm{T}$, p.Ala547Ser ${ }^{44}$ with similar allele frequencies of $14 \%$ in patients and $13 \%$ in controls. Interestingly, in three patients with that Ala547Ser variation, we detected an additional heterozygous pathogenic mutation: (GUCY2D:p.Pro701Ser (ARRP patient 25855), RPGRIPI:p.Aspl114Gly (IRP patient 25474). IRP patient 25140, as well as her unaffected father, had the RPGRIPI:p.Ala547Ser variation in combination with the RPGRIPI:p.Glu538Glufs2 mutation. The latter indicates that the p.Ala547Ser sequence change in combination with the p.Glu538Glufs2 mutation is not sufficient to lead to an RP phenotype.

\section{DISCUSSION}

Both clinically and genetically, there was a considerable overlap between our RP patients and our LCA patients. Clinically, visual field changes, as seen in RP, were present in RP patients and in two LCA patients. Nystagmus, which is frequently seen in LCA, was observed in LCA patients as well as in an IRP patient. In addition, fundoscopic changes were seen in ARRP, IRP, and LCA patients.

In summary, CRBI and GUCY2D mutations were found in RP patients as well as in LCA patients, RPE65 mutations were found only in LCA patients, and RPGRIPI mutations, previously only described in LCA, were newly identified in two RP patients.

\section{Mutations: frequency and distribution}

In this study we found nine mutations in $34 \%$ of our 35 patients. We identified mutations in $56 \%$ of our LCA patients, which corresponds well to published reports $(50 \%),{ }^{28}{ }^{29}$ although in contrast to the current study, most other studies did not screen for all known genes at once. In $27 \%$ of our ARRP patients we found one or two mutations, which is less than previously reported. ${ }^{12}$ This may reflect the fact that we screened our patients for LCA gene mutations, and not for all the known RP gene mutations. Screening our ARRP patients for additional known RP gene mutations will most probably lead to the detection of several more mutations.

In spite of the recessive nature of the disease, a second disease causing mutation was not found in nine of 12 patients. The design of our DHPLC analysis (sensitivity close to $99 \%$ ) makes it unlikely that a second exonic mutation in one of the screened genes was left undetected. ${ }^{47}{ }^{48}$ Obviously, it remains possible that promoter or regulatory sequences of the screened genes contain as yet unidentified mutations.

The spectrum of mutations in our study (CRBI (11\%), GUCY2D (11\%), RPE65 (6\%), and RPGRIPI (6\%)) shows only slight differences compared to those reported in the literature. This indicates that the gene distribution in our cohort is similar to juvenile RP and LCA populations worldwide. ${ }^{13} 14161918$

\section{New mutations}

Two new mutations were identified in this study. The first is the first the mutation reported in the intracellular C-terminal domain of GUCY2D:c.3283delC, p.Prol069ArgfsX37, in IRP 


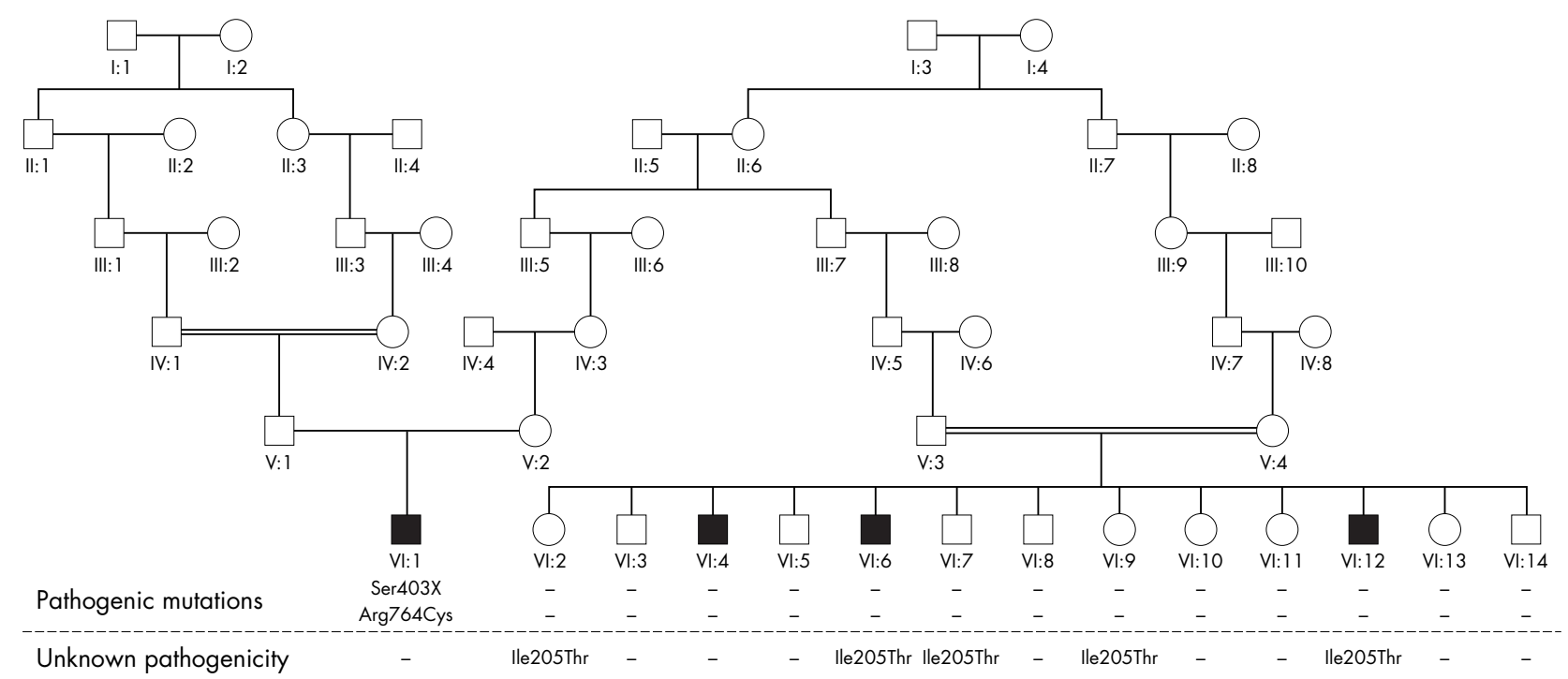

Figure 1 Family tree of a large consanguineous family with autosomal recessive retinitis pigmentosa (ARRP) with three different CRB1 sequence changes. Patient VI:I, with retinitis pigmentosa with PPRPE (preservation of the para-arteriolar retinal pigment epithelium, or RP12), had two mutations in the CRB1 gene (p.Ser403X and p.Arg764Cys), both identified in a previous study. ${ }^{14}$ The p.lle205Thr sequence change, previously reported as a disease causing mutation and as a polymorphism, ${ }_{43}^{53}$ was found in patients $\mathrm{VI}: 6$, and $\mathrm{VI}: 12$, and in unaffected siblings $\mathrm{Vl}: 2$, Vl:7 and VI:9. However, the sequence change was not found in patient $\mathrm{Vl}: 4$, which means that two as yet unidentified pathogenic mutations are present in this patient. Unless one of these was a spontaneous mutation in patient $\mathrm{Vl}: 4$, one of the unaffected parents (unavailable for mutation screening) carried two disease causing mutations, making him or her affected. In summary, even though we did not detect this sequence change in our control population, the lack of cosegregation with the disease phenotype in this family leads us to the conclusion that the p.lle205Thr sequence change is most likely polymorphic. Filled squares: retinitis pigmentosa patients.

patient 25556. The deletion creates a stop codon at position 1106 of the cDNA, which results in a larger, most likely unstable, mRNA or a dysfunctional protein. GUCY2D is a well conserved protein, containing an extracellular ANF receptor domain, a transmembrane domain, an intracellular protein kinase homology domain, and an intracellular guanylate cyclase domain. ${ }^{49}$ Mutations have been described in all these domains, ${ }^{16}{ }^{34}$ except for the intracellular C-terminal domain. The function of the latter domain is unknown. GUCY2D is one of the enzymes indirectly responsible for the regulation of phototransduction in the photoreceptor cells through regulation of cGMP levels. ${ }^{50}$ An altered GUCY2D protein could disturb this process, leading to an RP phenotype, as seen in this IRP patient. Patient 25556 had an age of onset and visual field changes compatible with an RP phenotype. However, the lack of fundoscopic changes and the presence of nystagmus indicate a phenotypic overlap with LCA.

The second new mutation identified in this study is RPGRIP1:c.1614_1623del, p.Glu538Glufs2 in IRP patient 25140. A stop codon is introduced at position 540 of the cDNA, which will prevent the transcription of the protein kinase $\mathrm{C}$ conserved region $2(\mathrm{C} 2)$ and the $R P G R$ binding domain. ${ }^{51}$ The RPGRIPI protein is localised in the connecting cilia of human cone and rod photoreceptors that connect inner and outer segments, where it binds RPGR to the cilium. $^{51}$ RPGR plays a role in the maintenance of photoreceptor viability..$^{52} R P G R$ mutations were previously found in $\mathrm{X}$ linked RP, and RPGRIPI mutations are known to cause LCA. ${ }^{19}{ }^{31}$ Therefore we consider this RPGRIPI deletion likely to be involved in RP, even though a second mutation was not found in this patient (25140). Patient 25140 had a constricted visual field, a visual acuity at age 15 of 0.1 , and no nystagmus, which goes against the diagnosis of LCA. However, the absence of fundoscopic changes, the relatively early onset ( 1.5 years), and the presence of colour vision defects are more typical of an LCA related phenotype. This patient is a typical example of the phenotypic overlap that exists between juvenile RP and LCA. ${ }^{7}$

\section{Polymorphic sequence changes}

We established or confirmed the polymorphic nature of three sequence changes previously reported as pathogenic mutations. The first (AIPL1:c.286G $\rightarrow$ A, p.Val96Ile) was previously described as a disease causing mutation. ${ }^{13}$ We consider it to be a rare neutral polymorphic change because of its high allele frequency $(7 \%)$ in our control subjects. The second sequence change we report to be polymorphic (CRB1:c.6147T $\rightarrow$ C, p.Ile205Thr) was initially described as a disease causing mutation in a Spanish ARRP family. ${ }^{43}$ More recently it was reported in a Dutch study as a polymorphic sequence change. ${ }^{53}$ We find it heterozygously in a single family where is does not co-segregate with the disease phenotype (fig 1). Moreover, the change is absent in 192 control chromosomes, which lead us to suggest that Ile205Thr is a rare neutral sequence change. The pathogenic nature of the third sequence change (RPGRIPI:c.1639G $\rightarrow \mathrm{T}$, p.Ala547Ser) is unclear in published reports. It was described as a polymorphism, ${ }^{19}$ and a disease causing mutation. ${ }^{44}$ The high frequency of this sequence change in our control group (13\%) suggests RPGRIPI:p.Ala547Ser is indeed a neutral polymorphism. We found it heterozygously along with a homozygous disease causing RPE65 mutation in LCA patient 9359. Furthermore, the presence of Ala547Ser in the unaffected parents of LCA patient 9359 and IRP patient 25140, along with other heterozygous mutations, suggests it does not cause a disease phenotype.

\section{Conclusions}

We observed a large overlap in the mutation spectrum and the clinical signs in the juvenile ARRP, LCA, and juvenile IRP patients, both in our study and in the literature. ${ }^{4} 71422343654$ Our clinical data, combined with the mutation spectrum found in our patients, do not provide hard evidence that a clear distinction between juvenile RP and LCA can be made. We expect that eventually more clarity will come from molecular genetic analysis of the underlying gene defects. 


\section{ACKNOWLEDGEMENTS}

We thank all patients for their participation in this study.

\section{Authors' affiliations}

J C Booii, R J Floriin, J B ten Brink, W Loves, Department of Clinical and Molecular Ophthalmogenetics, The Netherlands Ophthalmic Research Institute, Royal Netherlands Academy of Arts and Sciences, Amsterdam, Netherlands

A A B Bergen, P T V M de Jong, Department of Clinical and Molecular Ophthalmogenetics, The Netherlands Ophthalmic Research Institute, Royal Netherlands Academy of Arts and Sciences, Amsterdam F Meire, Department of Ophthalmology, University of Gent, Gent, Belgium

M J van Schooneveld, Department of Ophthalmology, University of Utrecht, Utrecht, Netherlands

Competing interests: none declared

Correspondence to: Dr Prof A A B Bergen, Department of Ophthalmogenetics, Meibergdreef 47, 1105 BA Amsterdam, Netherlands; a.bergen@ioi.knaw.nl

Received 20 May 2005

Revised version received 13 July 2005

Accepted for publication 18 July 2005

\section{REFERENCES}

1 Haim M. Epidemiology of retinitis pigmentosa in Denmark. Acta Ophthalmol Scand Suppl 2002;(233): 1-34

2 Koenekoop RK. An overview of Leber congenital amaurosis: a model to understand human retinal development. Surv Ophthalmol 2004;49:379-98.

3 Lorenz B, Gyurus P, Preising M, Bremser D, Gu S, Andrassi M, Gerth C, Gal A. Early-onset severe rod-cone dystrophy in young children with RPE65 mutations. Invest Ophthalmol Vis Sci 2000;41:2735-42.

4 Morimura H, Fishman GA, Grover SA, Fulton AB, Berson EL, Dryja TP. Mutations in the RPE65 gene in patients with autosomal recessive retinitis pigmentosa or Leber congenital amaurosis. Proc Natl Acad Sci USA 1998;95:3088-93.

5 Merin S, Auerbach E. Retinitis pigmentosa. Surv Ophthalmol 1976;20:303-46.

6 Perrault I, Rozet JM, Gerber S, Ghazi I, Leowski C, Ducroq D, Souied E, Dufier JL, Munnich A, Kaplan J.' Leber congenital amaurosis. Mol Genet Metab 1999;68:200-8

7 Rivolta C, Sharon D, DeAngelis MM, Dryja TP. Retinitis pigmentosa and allied diseases: numerous diseases, genes, and inheritance patterns. Hum Mol Genet 2002;11:1219-27.

8 van den Born LI, Bergen AA, Bleeker-Wagemakers EM. A retrospective study of registered retinitis pigmentosa patients in The Netherlands. Ophthalmic Paediatr Genet 1992;13:227-36.

9 Kajiwara K, Berson EL, Dryja TP. Digenic retinitis pigmentosa due to mutations at the unlinked peripherin/RDS and ROM1 loci. Science 1994;264:1604-8.

10 Thompson DA, McHenry CL, Li Y, Richards JE, Othman MI, Schwinger E, Vollrath D, Jacobson SG, Gal A. Retinal dystrophy due to paternal isodisomy for chromosome 1 or chromosome 2, with homoallelism for mutations in RPE65 or MERTK, respectively. Am J Hum Genet 2002;70:224-9.

11 Phelan JK, Bok D. A brief review of retinitis pigmentosa and the identified retinitis pigmentosa genes. Mol Vis 2000;6:116-24.

12 Website. (www.sph.uth.tmc.edu/retnet/disease.htm).

13 Sohocki MM, Perrault I, Leroy BP, Payne AM, Dharmaraj S, Bhattacharya SS, Kaplan J, Maumenee IH, Koenekoop R, Meire FM, Birch DG, Heckenlively JR, Daiger SP. Prevalence of AIPL1 mutations in inherited retinal degenerative disease. Mol Genet Metab 2000;70:142-50.

14 den Hollander Al, ten Brink JB, de Kok YJ, van Soest S, van den Born LI, van Driel MA, van de Pol DJ, Payne AM, Bhattacharya SS, Kellner U, Hoyng CB, Westerveld A, Brunner HG, Bleeker-Wagemakers EM, Deutman AF, Heckenlively JR, Cremers FP, Bergen AA. Mutations in a human homologue of Drosophila crumbs cause retinitis pigmentosa (RP12). Nat Genet 1999;23:217-21.

15 Freund CL, Gregory-Evans CY, Furukawa T, Papaioannou M, Looser J, Ploder L, Bellingham J, Ng D, Herbrick JA, Duncan A, Scherer SW, Tsui LC, Loutradis-Anagnostou A, Jacobson SG, Cepko CL, Bhattacharya SS, Mclnnes RR. Cone-rod dystrophy due to mutations in a novel photoreceptorspecific homeobox gene (CRX) essential for maintenance of the photoreceptor. Cell 1997;91:543-53.

16 Perrault I, Rozet JM, Calvas P, Gerber S, Camuzat A, Dollfus H, Chatelin S Souied E, Ghazi I, Leowski C, Bonnemaison M, Le Paslier D, Frezal J, Dufier JL, Pittler S, Munnich A, Kaplan J. Retinal-specific guanylate cyclase gene mutations in Leber's congenital amaurosis. Nat Genet 1996;14:461-4.

17 Haeseleer F, Jang GF, Imanishi Y, Driessen CA, Matsumura M, Nelson PS, Palczewski K. Dual-substrate specificity short chain retinol dehydrogenases from the vertebrate retina. J Biol Chem 2002;277:45537-46.

18 Marlhens F, Bareil C, Griffoin JM, Zrenner E, Amalric P, Eliaou C, Liu SY, Harris E, Redmond TM, Arnaud B, Claustres M, Hamel CP. Mutations in RPE65 cause Leber's congenital amaurosis. Nat Genet 1997;17:139-41.
19 Dryja TP, Adams SM, Grimsby JL, McGee TL, Hong DH, Li T, Andreasson S, Berson EL. Null RPGRIP1 alleles in patients with Leber congenital amaurosis. Am J Hum Genet 2001;68:1295-8.

20 North MA, Naggert JK, Yan Y, Noben-Trauth K, Nishina PM. Molecular characterization of TUB, TULP1, and TULP2, members of the novel tubby gene family and their possible relation to ocular diseases. Proc Natl Acad Sci USA 1997;94:3128-33.

21 Hagstrom SA, North MA, Nishina PL, Berson EL, Dryja TP. Recessive mutations in the gene encoding the tubby-like protein TULP1 in patients with retinitis pigmentosa. Nat Genet 1998;18:174-6.

22 den Hollander Al, Heckenlively JR, van den Born LI, de Kok YJ, van der VeldeVisser SD, Kellner U, Jurklies B, van Schooneveld MJ, Blankenagel A Rohrschneider K, Wissinger B, Cruysberg JR, Deutman AF, Brunner HG, Apfelstedt-Sylla E, Hoyng CB, Cremers FP. Leber congenital amaurosis and retinitis pigmentosa with Coats-like exudative vasculopathy are associated with mutations in the crumbs homologue 1 (CRB1) gene. Am J Hum Genet $2001 ; 69: 198-203$

23 Perrault I, Hanein S, Gerber S, Lebail B, Vlajnik P, Barbet F, Ducroq D Dufier JL, Munnich A, Kaplan J, Rozet JM. A novel mutation in the GUCY2D gene responsible for an early onset severe RP different from the usual GUCY2D-LCA phenotype. Hum Mutat 2005;25:222.

24 Perrault I, Hanein S, Gerber S, Barbet F, Ducroq D, Dollfus H, Hamel C, Dufier JL, Munnich A, Kaplan J, Rozet JM. Retinal dehydrogenase 12 (RDH12) mutations in Leber congenital amaurosis. Am J Hum Genet 2004:75:639-46.

25 Janecke AR, Thompson DA, Utermann G, Becker C, Hubner CA, Schmid E, McHenry CL, Nair AR, Ruschendorf F, Heckenlively J, Wissinger B, Nurnberg P, Gal A. Mutations in RDH1 2 encoding a photoreceptor cell retinol dehydrogenase cause childhood-onset severe retinal dystrophy. Nat Genet 2004;36:850-4.

26 Baneriee P, Kleyn PW, Knowles JA, Lewis CA, Ross BM, Parano E, Kovats SG, Lee JJ, Penchaszadeh GK, OH J, Jacobson SG, Gilliam TC. TULPI mutation in two extended Dominican kindreds with autosomal recessive retinitis pigmentosa. Nat Genet 1998;18:177-9.

27 Gu S, Lennon A, Li Y, Lorenz B, Fossarello M, North M, Gal A, Wright A. Tubby-like protein-1 mutations in autosomal recessive retinitis pigmentosa. Lancet 1998;351:1103-4

28 Hanein S, Perrault I, Gerber S, Tanguy G, Barbet F, Ducroq D, Calvas P, Dollfus H, Hamel C, Lopponen T, Munier F, Santos L, Shalev S, Zafeiriou D, Dufier JL, Munnich A, Rozet JM, Kaplan J. Leber congenital amaurosis: comprehensive survey of the genetic heterogeneity, refinement of the clinical definition, and genotype-phenotype correlations as a strategy for molecular diagnosis. Hum Mutat 2004:23:306-17.

29 Cremers FP, van den Hurk JA, den Hollander Al. Molecular genetics of Leber congenital amaurosis. Hum Mol Genet 2002;11:1169-76.

30 Miller S A, Dykes DD, Polesky HF. A simple salting out procedure for extracting DNA from human nucleated cells. Nucleic Acids Res $1988 ; 16: 1215$.

31 Gerber S, Perrault I, Hanein S, Barbet F, Ducroq D, Ghazi I, MartinCoignard D, Leowski C, Homfray T, Dufier JL, Munnich A, Kaplan J, Rozet JM. Complete exon-intron structure of the RPGR-interacting protein (RPGRIP1) gene allows the identification of mutations underlying Leber congenital amaurosis. Eur J Hum Genet 2001;9:561-71.

32 Website. (http://www.retina-international.org/sci-news/mutation.htm).

33 den Dunnen JT, Antonarakis SE. Mutation nomenclature extensions and suggestions to describe complex mutations: a discussion. Hum Mutat 2000;15:7-12.

34 Dharmaraj SR, Silva ER, Pina AL, Li YY, Yang JM, Carter CR, Loyer MK, ElHilali HK, Traboulsi EK, Sundin OK, Zhu DK, Koenekoop RK, Maumenee IH. Mutational analysis and clinical correlation in Leber congenital amaurosis. Ophthalmic Genet 2000;21:135-50.

35 Lotery AJ, Namperumalsamy P, Jacobson SG, Weleber RG, Fishman GA, Musarella MA, Hoyt CS, Heon E, Levin A, Jan J, Lam B, Carr RE, Franklin A, Radha S, Andorf JL, Sheffield VC, Stone EM. Mutation analysis of 3 genes in patients with Leber congenital amaurosis. Arch Ophthalmol 2000;118:538-43

36 Thompson DA, Gyurus P, Fleischer LL, Bingham EL, McHenry CL, ApfelstedtSylla E, Zrenner E, Lorenz B, Richards JE, Jacobson SG, Sieving PA, Gal A. Genetics and phenotypes of RPE65 mutations in inherited retinal degeneration. Invest Ophthalmol Vis Sci 2000;41:4293-9.

37 Perrault I, Rozet JM, Ghazi I, Leowski C, Bonnemaison M Gerber S Ducroq D, Cabot A, Souied E, Dufier JL, Munnich A, Kaplan J. Different functional outcome of RetGCl and RPE65 gene mutations in Leber congenital amaurosis. Am J Hum Genet 1999;64:1225-8.

38 Shapiro MB, Senapathy P. RNA splice junctions of different classes of eukaryotes: sequence statistics and functional implications in gene expression. Nucleic Acids Res 1987;15:7155-74

39 Website. (http://www.genomic.unimelb.edu.au/mdi/mutnomen/)

40 Lotery AJ, Namperumalsamy P, Jacobson SG, Weleber RG, Fishman GA, Musarella MA, Hoyt CS, Heon E, Levin A, Jan J, Lam B, Carr RE, Franklin A, Radha S, Andorf JL, Sheffield VC, Stone EM. Mutation analysis of 3 genes in patients with Leber congenital amaurosis. Arch Ophthalmol 2000;1 18:538-43

41 Website. (http://www.genet.sickkids.on.ca/ ali/splicesitefinder.html).

42 Website. (http://genes.mit.edu/burgelab/rescue-ese/).

43 Bernal S, Calaf M, Garcia-Hoyos M, Garcia-Sandoval B, Rosell J, Adan A, Ayuso C, Baiget M. Study of the involvement of the RGR, CRPB1, and CRB genes in the pathogenesis of autosomal recessive retinitis pigmentosa. J Med Genet 2003:40:e89.

44 Hameed A, Abid A, Aziz A, Ismail M, Mehdi SQ, Khaliq S. Evidence of RPGRIP1 gene mutations associated with recessive cone-rod dystrophy. J Med Genet 2003;40:616-19. 
45 Gerber S, Perrault I, Hanein S, Barbet F, Ducroq D, Ghazi I, MartinCoignard D, Leowski C, Homfray T, Dufier JL, Munnich A, Kaplan J, Rozet JM Functional analyses of RetGCl missense mutations identified in Leber's congenital amaurosis [abstract]. Invest Ophthalmol Vis Sci 2000;PS533.

46 Loyer M, Pina AL, El Hilali E, Vallelado A, Lee Y, Zhu D, Maumenee I, Koenekoop R. Novel mutations in the retinal guanylyl cyclase gene in new populations of patients with Lebers's congenital amaurosis [abstract]. Invest Ophthalmol Vis Sci 1998;39:S295.

47 Yamanoshita O, Kubota T, Hou J, Ping YM, Zhang XL, Li XP, Li SS, Li XX, Zhu DC, Fukushima Y, Nakajima T. DHPLC is superior to SSCP in screening p53 mutations in esophageal cancer tissues. Int J Cancer 2005; 1 14:74-9.

48 Xiao W, Oefner PJ. Denaturing high-performance liquid chromatography: a review. Hum Mutat 2001; 17:439-74.

49 Website. (http://www.sanger.ac.uk/cgi-bin/Pfam/ swisspfamget. pl? name $=$ Q02846).

50 Perrault I, Rozet JM, Gerber S, Ghazi I, Ducroq D, Souied E, Leowski C, Bonnemaison M, Dufier JL, Munnich A, Kaplan J. Spectrum of
retGCl mutations in Leber's congenital amaurosis. Eur J Hum Genet 2000;8:578-82.

51 Hong DH, Yue G, Adamian M, Li T. Retinitis pigmentosa GTPase regulator (RPGRr)-interacting protein is stably associated with the photoreceptor ciliary axoneme and anchors RPGR to the connecting cilium. J Biol Chem 2001;276:12091-9.

52 Hong DH, Pawlyk BS, Shang J, Sandberg MA, Berson EL, Li T. A retinitis pigmentosa GTPase regulator (RPGR)-deficient mouse model for X-linked retinitis pigmentosa (RP3). Proc Natl Acad Sci USA 2000:97:3649-54.

53 den Hollander Al, Davis J, van der Velde-Visser SD, Zonneveld MN, Pierrottet CO, Koenekoop RK, Kellner U, van den Born LI, Heckenlively JR, Hoyng CB, Handford PA, Roepman R, Cremers FP. CRB 1 mutation spectrum in inherited retinal dystrophies. Hum Mutat 2004;24:355-69.

54 Lotery AJ, Jacobson SG, Fishman GA, Weleber RG, Fulton $A B$,

Namperumalsamy P, Heon E, Levin AV, Grover S, Rosenow JR, Kopp KK, Sheffield VC, Stone EM. Mutations in the CRB 1 gene cause Leber congenital amaurosis. Arch Ophthalmol 2001;119:415-20. 